\title{
Conquistar o Tertium Datur: Sloterdijk em Defesa DE UMA “aNTRopologia CibernéticA” (ENTRE HeIdegGer, GÜNTHER E LATOUR $)^{1}$
}

\author{
Mauricio Fernando Pitta ${ }^{2}$ \\ José Fernandes Weber ${ }^{3}$
}

Resumo: Martin Heidegger desenvolveu uma análise da metafísica e da tecnologia que questionava radicalmente seus pressupostos ontológicos. Contudo, para Peter Sloterdijk, autor de uma revisão do motivo da clareira (Lichtung) heideggeriana intitulada Domesticação do ser: clarificando a clareira, Heidegger padece daquilo mesmo que ele critica: uma pendência para a ontologia clássica que, desde pelo menos Platão e Aristóteles, separa o ser e o nada, basila o princípio de bivalência na lógica, excluindo qualquer terceira possibilidade, e permite os dualismos constitutivos da metafísica. Seguindo o antropólogo Bruno Latour, o qual evidenciara que "modernidade" não é senão uma crença na cisão entre os polos de forma e matéria, sujeito e objeto, natureza e cultura, também Sloterdijk vai atribuir a Heidegger a pendência à ontologia clássica, elevada ao nível da cisão entre o ôntico e o ontológico. Diante disso, o que sugere Sloterdijk? Uma alternativa à ontologia clássica na cibernética de Wiener e Günther, reatando os laços, desfeitos por Heidegger, entre ontologia e antropologia. Este trabalho tem por intenção articular a crítica de Sloterdijk, a investigação de Latour e a revisáo ontológicológica de Günther, a fim de assentar bases para compreensão do projeto sloterdijkiano de se pensar a antropologia a partir de pressupostos cibernéticos.

Palavras-Chave: Antropologia. Cibernética. Lógicas não-clássicas. Metafísica. Ontologia.

${ }^{1} \mathrm{O}$ presente trabalho foi realizado com apoio da Coordenação de Aperfeiçoamento de Pessoal de Nível Superior - Brasil (CAPES) - Código de Financiamento 001, e do CNPq (Bolsa Produtividade em Pesquisa, projeto "Filosofia, existência e finitude: Eugen Fink e a legitimidade de uma antropologia filosófica”).

2 Professor substituto de Filosofia pela Universidade Federal de Uberlândia (UFU), Uberlândia, MG - Brasil. Doutorando em Filosofia pela Universidade Federal do Paraná, mestre em Filosofia Contemporânea pela Universidade Estadual de Londrina, e bolsista financiado pelo programa CAPES/ DS, da Coordenação de Aperfeiçoamento de Pessoal de Nível Superior. (D) https://orcid.org/00000002-9642-4072 E-mail: mauriciopitta@hotmail.com

3 Professor Titular (Adjunto B) da Universidade Estadual de Londrina (UEL), Londrina, PR - Brasil. Doutor em Educação (Filosofia da Educação) pela Universidade Estadual de Campinas, Bolsista Produtividade do CNPq (PQ-2). (D) https://orcid.org/0000-0001-8402-7224 E-mail: jweber@ uel.br

http://dx.doi.org/10.1590/0101-3173.2020.v43n1.11.p189

This is an open-access article distributed under the terms of the Creative Commons Attribution License. 
$\mathrm{Na}$ questão diretriz do projeto ontológico de Martin Heidegger, filósofo alemão do século XX responsável por resgatar a importância de se questionar a ontologia em geral, vigora uma relação forte entre esquecimento do ser e diferença ontológica (HEIDEGGER, 2012, p. 2-5; 2006, p. 66). Se o ser, no descobrimento da totalidade do ente, já se encobre como condição de possibilidade, é justamente pela cinética dupla de retração e mostração que se pode falar em diferença ontológica, isto é, velamento e esquecimento do ser junto ao desvelamento e presença do ente na totalidade (2000, p. 267; 2006, p. 41). A empreitada de Heidegger, em síntese, intende resgatar, diante do esquecimento, a situação na qual se permite voltar à diferença ela mesma, situação essa que é a do retorno ao habitar primordial na casa da linguagem, provedora "universal" de ser ao ente (1976, p. 313; 2000, p. 220). Mas tal retorno deve resguardar, isto é, velar (no sentido de "cuidar de") o velamento mesmo. Aí reside a postura do pastoreio, a qual Heidegger evoca aos poetas e pensadores, possibilitando que a linguagem diga o ser no seu monólogo mais próprio, em seu tempo propício (1976, p. 331). Dessa forma, em tempos da maquinação técnica absoluta do real, na qual o ente se mostra destituído de ser — isto é, como valor arbitrário e estoque de forças (2000, p. 15-18) —, que o filósofo batiza de Gestell, só o pastoreio diante dessa técnica que encobre o ser do ente como um todo em vista de seu "ser estoque" permite que tal retorno se faça possível. Todavia, frente à questão diretriz de Heidegger, a pergunta que se póe no espírito do deslocamento operado por Peter Sloterdijk, foco primário do presente artigo, é parelha àquela que, citada por Sloterdijk (2001, p. 160), articula Bruno Latour (2013), em tom de provocação: "Houve realmente alguém que esqueceu o ser?” (p. 66). ${ }^{4}$

\footnotetext{
${ }^{4}$ A princípio, pode parecer arbitrária a colocação, lado a lado, das discussóes de Sloterdijk e de Latour, preocupados com campos de problemas, de início, tão diversos. Porém, logo na leitura das primeiras páginas de Domesticação do ser: clarificando a clareira (2001, p. 142-234) — onde o filósofo alemão questiona a precedência do ontológico na diferença heideggeriana - , a passagem citada logo mais, extraída do livro Jamais fomos modernos: ensaio de uma antropologia simétrica (2013), escrito pelo pesquisador francês, em 1994, e que, nas palavras de Sloterdijk, "se afasta com necessária clareza com relação ao pietismo não empírico do recordar-do-ser [Seins-Andenkens]" (2001, p. 160, tradução nossa), aparece como indício de que suas empresas são afins. Dessa citação, seguiram-se, nos anos seguintes, artigos de Latour (cf. 2009a; 2009b) os quais afirmavam haver, entre o conceito central da antropologia latouriana, "redes", e as "esferas" de Sloterdijk, uma forte confluência, a ponto de serem conceitos, em certo sentido, transmutáveis. O diálogo entre os dois, situado, entre outros, sob o pano de fundo da antropologia simétrica e das pesquisas em ontologia cibernética, e que, do ponto de vista de Sloterdijk, demonstra a pertença de ambos, junto a pensadores como Gilles Deleuze e Michel Serres, a uma espécie de "gigantomaquia [Gigantenkampf] do pensamento" (2001, p. 218, tradução nossa), reaparecerá com frequência, doravante, neste artigo.
} 
Sloterdijk, na esteira de Latour, pretende repensar a diferença ontológica para poder desdobrar adequadamente a condição antropogênica do humanismo e, com isso, se defrontar com a questão, para ele, mal resolvida, da espacialidade em Heidegger (SLOTERDIJK, 1998, p. 336345; PITTA, 2017). A pergunta feita por Latour, no tocante às preocupaçôes teóricas do pensador do ser, também serve para a questão de um possível vir a ser do Dasein, em vista de sua condição de não-dado. Se o ente que um dia viria a ser o mortal da clareira pôde, de fato, chegar à clareira, de que forma investigar esse movimento, senáo pondo em equilíbrio a balança assimétrica da diferença ontológica, a fim de abrir possibilidade de explicitar como o ente não-humano ôntico se permitiu ter uma precedência humana ôntico-ontológica, vislumbrando, assim, o mundo diante de si? A clareira, nesse sentido, deve ser repensada como ponto fulcral da própria hominização, isto é, como "resultado da história, quiçá [como] o acontecimento [Ereignis] por excelência.” (SLOTERDIJK, 2001, p. 159, tradução nossa). Portanto, ela não pode prescindir de uma investigação ôntica (sobretudo por parte da antropologia simétrica e da paleoantropologia), associada à ontológica, para que seja devidamente "clarificada" (verdeutlicht).

Sobre que bases, porém, pode Sloterdijk questionar a noção de diferença ontológica de Heidegger? Como Latour (2013, p. 66) consegue, frente a sua pergunta, responder que somente esquece o ser "aquele que acredita sinceramente que o Ser foi esquecido para sempre”? Como é possível que o ontológico seja posto no mesmo nível que o ôntico, considerando que o filósofo de Meßkirch já advertira inúmeras vezes, de forma coerente com sua investigação, para a possibilidade de aprofundamento do esvaziamento absurdo da Gestell como resultado inquietante do desenvolvimento cego das ciências positivas, ônticas, que não põem em questáo seus próprios pressupostos ontológicos e se desdobram sobre a substancialização do ser? Por conseguinte, como fazer uma antropologia do processo histórico da clareira, se a própria antropologia, como também a psicologia, a psicanálise, a biologia, a fisiologia e todas as ciências que pautam seus aportes teóricos na pressuposição de um sentido de ser e de um sentido de humano metafísicos, necessitam de uma depuração ontológica (HEIDEGGER, 2012, \$10), como já aconselhara Heidegger (1987), por exemplo, a Medard Boss e aos criadores da psicologia existencial (Daseinsanalyse), na metade do século passado?

Para Heidegger, é justamente por causa de uma linguagem, a qual não faculta que o ser se dê explicitamente e de partida, a não ser sobre uma 
presentificação ôntica, que a pesquisa científica, pautada cada vez em determinada região do ente, não pode equivaler às consideraçôes ontológicas, que, por fim, se veem às voltas com a renúncia e o pastoreio poéticos. No entanto, Sloterdijk volta o "feitiço" heideggeriano contra seu "feiticeiro" e salienta como o pensador do ser se mantém no mesmo registro da tradição. "Também Heidegger, por inegável que seja sua importância como destruidor da metafísica, esteve em parte preso a uma gramática que tem por pressuposto uma ontologia totalmente insustentável e uma lógica insuficiente." (SLOTERDIJK, 2001, p. 216, tradução nossa) Sinal disso poderia ser encontrado, entre outros, em sua própria recaída nas tautologias ontológicas inescapáveis, que apontam os limites da linguagem, em seu recurso tardio aos poetas como únicos porta-vozes dos acenos do ser, diante da insuficiência da metafísica e na postura renunciadora do pastoreio que o pensador advoga como única postura saudável diante do niilismo da Gestell e do inescapável acabamento da metafísica.

A ontologia e a lógica às quais Sloterdijk se refere são aquelas que provêm desde, ao menos, de Platão e Aristóteles, isto é, a ontologia monovalente e a lógica bivalente. ${ }^{5}$ As duas são complementares e correspondentes. A preocupação de Heidegger com a "unidade de um conceito originário de ser” (HEIDEGGER, 1975, p. 219, tradução nossa) deriva da dívida que seu pensamento tem para com a ontologia aristotélica (VALENTIM, 2013, p. 6), cujo aporte central é a unidade substancial do ser, ov̉oí $\alpha$, diante dos múltiplos modos de ser acidentais. ${ }^{6}$ Embora Heidegger não conceba o ser sob a égide do ente e da substância, voltando-se, com isso, contra Aristóteles (no sentido de "em uma direção mais fundamental" que o estagirita), é com o intuito de "encontrar uma ciência originária que não se desarticule das vivências singulares do ente [...], mas que descubra nessas vivências mesmas o ponto de conexão com o princípio transcendente de toda verdade" (CASANOVA, 2012, p. 23) que o filósofo alemão vai procurar desenvolver sua ontologia.

5 Ontologia monovalente (ou "clássica", como a ela se refere Gotthard Günther [2004]), significa simplesmente uma ontologia que tem por único valor o "ser" (em sentido heideggeriano: o ente) como "realidade", e opõe a isso o não-ser (isto é, o "não-ente", o "nada", que não é valor nenhum, mas apenas o negativo). Lógica bivalente, por outro lado, é aquela lógica, comumente chamada de "lógica clássica”, a qual opera por dois únicos valores-verdade, a saber, pela lei da não-contradição e pela recusa de um terceiro valor. A lógica bivalente corresponde (mas não se confunde, por ser de outro domínio) à ontologia monovalente, na medida em que seu valor de verdade serve para verificar a ocorrência do ente no domínio do real, enquanto seu valor de falsidade atesta sua não ocorrência.

${ }^{6} \mathrm{O}$ intenso diálogo de Heidegger com Aristóteles não se restringe aos problemas da ontologia. Também a filosofia prática aristotélica é decisiva para a elaboração de algumas noçôes heideggerianas, dentre as quais se destaca a noção de facticidade, central em Ser e tempo. A esse respeito, cf. VOLPI, 2013. 
Desdobrando suas investigaçôes no caminho de uma linguagem que mantém agrilhoado qualquer pensador em divisóes abissais entre "ser" (ente) e "não-ser" (nada), humano e não-humano (VALENTIM, 2013), alma e corpo, forma e matéria, sujeito e objeto, liberdade e determinismo, "nós" e "eles", não é nada absurdo que seja exigido uma depuração ontológica (e, nesse sentido, também lógica e gramatical) de toda e qualquer ciência positiva e que, portanto, antes de seus desdobramentos regionais, seja necessário reformular a ontologia como um todo. Assim, para Sloterdijk, as intençôes do projeto heideggeriano rumam a um objetivo afim ao dele, mas sucumbem nos mesmos pressupostos da tradição que ele intenta desconstruir.

Seria só a partir de uma virada cibernética, operada por volta de 1950 por teóricos como Norbert Wiener, William Ross Ashby, Heinz von Foerster e Gotthard Günther, que Sloterdijk (2001, p. 216-217) afirma abrir-se campo para investigaçôes científicas que não isolem o objeto científico, o sujeito do conhecimento, bem como a natureza e a sociedade, o ôntico e o ontológico. Só assim é possível uma antropologia tal que, ciente de seus pressupostos ontológicos, permita compreender o processo antropogenético do Dasein e, com isso, dar novo influxo para uma compreensão do (lugar do) humano na era da Gestell. Por isso, serão necessários dois breves desvios - um pelos pressupostos da cibernética, importantes para compreensão do que está em jogo na argumentação de Sloterdijk, e outro pela crítica de um dos teóricos da cibernética às bases lógicas e ontológicas da tradição - para compreender como a cibernética influenciaria no afastamento de Sloterdijk com relação ao projeto heideggeriano.

Heidegger, por sua vez, foi um crítico tenaz da cibernética nascente. Já em O fim da filosofia e a tarefa do pensamento (HEIDEGGER, [1964] 2007), a partir da leitura de Cibernética: ou controle e comunicaçáo no animal e na máquina (WIENER, [1952] 1985), de Wiener, um dos textos iniciais da cibernética, o filósofo diz que esse novo ramo do conhecimento, em sua abrangência, totalização e unificação da totalidade do ente como fluxo variável, retroalimentacional e sistêmico entre informação e entropia, representa a mecanização e o esvaziamento do humano, do mundo, do pensamento e da linguagem.

A cibernética foi uma ciência nascente que possibilitou, por seu caráter transdisciplinar, a junção de diversas áreas do conhecimento, estilhaçadas durante os séculos XIX e XX (GÜNTHER, 2004, p. 18). Essa unificação, em parte atingida pela ontologia cibernética, fora por muito tempo objetivo da ontologia clássica. Diga-se de passagem, essa característica unificadora 
provém, antes, da Teoria geral dos sistemas, publicada em 1945, por Ludwig von Bertalanffy (1969), ramo da biologia moderna que teve influência sobre a cibernética, a ecologia, a sociologia, o direito, a psicologia, a neurofisiologia do conhecimento, a medicina, a psiquiatria, as teorias da administração, a economia política, a química e a física (LIMA, 2005, p. 253). Além disso, a cibernética de Wiener (1985) e Ashby (1956) constituiu-se em torno da busca de "desenvolver uma linguagem e técnicas" que os capacitassem a lidar "com o problema do controle e da comunicação em geral, e a descobrir o repertório de técnicas e ideias adequadas para classificar-lhe as manifestaçóes específicas sob a rubrica de certos conceitos." (WIENER, 1958, p. 17). Cabe, no entanto, o questionamento sobre que tipo de controle e que tipo de comunicação são esses, e se essa priorização do controle e da comunicação implica necessariamente o "perigo" que o filósofo de Meßkirch atribui ao niilismo da Gestell.

Controlar significa, para a cibernética, desenvolver estratégias de ordenação contra "a desorganização em trânsito" (WIENER, 1958, p. 17) a que está sujeita a comunicação. Pressuposto, aí, está o conceito, emprestado pela cibernética da termodinâmica ${ }^{8}$, de entropia, isto é, de desorganização ou desinformação, ou, em outras palavras, "desordem crescente em um sistema em virtude da perda de potencial energético (isto é, degradação).” (MORAN, 2010, p. 414). "A tendência característica da entropia", em um sistema fechado qualquer, "é a de aumentar" (WIENER, 1958, p. 14) até atingir um valor máximo". Por conseguinte, entropia vem ligada à probabilidade. "Conforme aumenta a entropia," segundo Wiener,

[...] o universo, e todos os sistemas fechados do universo, tendem naturalmente a se deteriorar e a perder a nitidez, a passar de um estado de mínima a outro de máxima probabilidade; de um estado de organizaçáo e diferenciação, em que existem formas e distinções, a um estado de caos e mesmice. No universo de Gibbs, a ordem é o menos provável e o caos o mais provável. (WIENER, 1958, p. 14).

\footnotetext{
7 Sobre a influência do neoplatonismo no nascimento da teoria dos sistemas e da cibernética, cf. LIMA, 2005, p. 253-286. A trilogia Esferas de Sloterdijk, sobretudo no final do primeiro volume (SLOTERDIJK, 1998) e ao longo de seu segundo volume (id., 1999), está salpicada de referências a Plotino, Agostinho, Nicolau de Cusa, Leibniz e outros, essenciais para a "história da esfera" sloterdijkiana, os quais aparecem já na epígrafe do livro de von Bertalanffy (cf. 1969, p. v), levando, segundo Lima, a "tocha olímpica" das heranças platônica, neoplatônica e mística até os tempos atuais da teoria dos sistemas. Sloterdijk, por sua vez, parece reconhecer a mesma dívida.

${ }^{8}$ Mais precisamente, pela leitura estatística, físicos como Willard Gibbs, James C. Maxwell e Ludwig Boltzmann fizeram da termodinâmica (cf. WIENER, 1958, p. 10). Essa leitura, por si só, já constitui, segundo Wiener, uma ruptura com a física newtoniana e, portanto, requer, como a física quântica, uma outra relação com a referência ao mundo físico em geral.
} 
Nesse sentido, a cibernética se constitui na articulação da tensão entre a tendência desordenadora, entrópica, do sistema e sua contratendência, neguentrópica. ${ }^{9}$ Por isso, a cibernética de Wiener não se fecha no conceito de entropia. Para além dele, é necessário considerar outros dois conceitos: informaçáo e retroalimentação (feedback). Eles, contudo, só fazem sentido ao se levar em conta o caráter ambiental ou ecológico da própria cibernética: "Em comunicação e controle, estamos sempre em luta contra a tendência da Natureza de degradar o orgânico e destruir o significativo" (WIENER, 1958, p. 17, grifo nosso) com a "Natureza" compreendida como exterioridade entrópica.

Ao nivelar viventes e máquinas como sistemas abertos — o que abre margem para se interpretar um sistema aberto como uma vida (WIENER, 1958, p. 32) —, isto é, como sistemas que não se esgotam na tendência probabilística de deformação, dependendo de uma interação com o ambiente, Wiener reconhece a influência de Jakob von Uexküll, responsável pelo conceito de Umwelt ("meio ambiente”), em sua cibernética: o sistema cibernético necessita da recepção controlada e local de mensagens do meio entrópico, para agir em contratendência neguentrópica, como ocorre com o círculo funcional de von Uexküll (2010, p. 49). "O processo de receber e utilizar informação é o processo de nosso ajuste às contingências do meio ambiente e de nosso efetivo viver nesse meio ambiente." (WIENER, 1958, p. 17-18, grifo nosso) Ajustar-se às contingências implica desenvolver um movimento contrário ao do exterior, isto é, um movimento contrário à da entropia. Assim, "é possível interpretar a informação conduzida por uma mensagem como sendo, essencialmente, o negativo de sua entropia e o logaritmo negativo de sua probabilidade." (WIENER, 1958, p. 21, grifos nossos). Informação é, portanto, diretamente proporcional à neguentropia. É para poder ajustar-se de acordo com as circunstâncias do meio externo e manter essa neguentropia que o sistema necessita de retroalimentação, isto é, do reajuste constante de sua resposta ao ambiente de acordo com a mensagem recebida ou, em outras palavras, "da capacidade de poder ajustar a conduta futura em função do desempenho pretérito.” (WIENER, 1958, p. 33). ${ }^{10}$

\footnotetext{
${ }^{9}$ Referente ao termo neg-entropy, "neg-entropia", "entropia negativa" ou "antientropia" (cf. WIENER, 1958; 1985; BATESON, 1999). Para facilitar a pronúncia e a absorção, no português, optamos aqui pelo uso do termo "neguentropia", sem o hífen.

${ }^{10}$ Outra formulação da noção pode ser encontrada em Gregory Bateson, responsável pela instauração de uma "epistemologia ecológica": "Em todos os sistemas cibernéticos [...], uma ação corretiva é acarretada por diferença. [...] O termo técnico 'informaçáo' pode ser sucintamente definido como qualquer diferença que faz diferença em algum evento posterior. Essa definição é fundamental para toda análise de organização e sistemas cibernéticos. A definição conecta tal análise com o resto da ciência, na qual causas de eventos não costumam ser diferenças, mas forças, impactos e afins. A conexão é
} 
Logo, o que a cibernética quer dizer com "controle" está em correlação direta com a relação ecológica do sistema ("vida”) com seu exterior e pressupóe o esforço constante de reverter localmente, no contexto do sistema, o movimento de deformação e de planificação. Em certo sentido, esse intento da cibernética parece se contrapor à vinculação que Heidegger postula entre ela e a homogeneização da Gestell, pois, a partir da equivalência entre informação e neguentropia, abre-se a possibilidade de questionar a tese de que a informação é equivalente à planificação da linguagem. Por seu caráter de produção de redundâncias, desinformativa, a Gestell se encontraria no ponto oposto ao da informação - ainda que essa informação seja suscetível de se desinformar, se planificar, se uniformizar. É necessário, contudo, ir mais a fundo na abordagem do impacto que concepçóes como a cibernética têm sobre as próprias bases do que está em questão, em vista da virada ontológica e lógica que, segundo Sloterdijk (2001, p. 216), teóricos desse movimento buscaram concretizar.

No caso, o autor de Esferas está se referindo, dentre os teóricos da cibernética, a Günther. Em uma leitura de uma de suas obras centrais, Ontologia cibernética e operaçóes transjuncionais (GÜNTHER, 2004), de 1962, texto onde o teórico apresenta os pressupostos básicos de questionamento dessa perspectiva clássica da ontologia e da lógica metafísicas, é possível entender de que forma Günther pretende desenvolver uma nova abordagem para complementar a ontologia e a lógica clássicas, as quais priorizam um dos âmbitos dos dualismos clássicos — ideia-sensibilidade, forma-matéria, sujeito-objeto etc. Para ele, é necessário reconstruir os pressupostos ontológicos e lógicos em vista dos próprios objetos que a cibernética (e, antes dela, a física quântica) colocaram em questáo. Nesse sentido, ele afirma que

[...] nossa ontologia presente (clássica) náo dá conta de "tudo". Ela exclui certos fenômenos do ser da investigaçáo científica, declarando-os de natureza irracional ou metafísica. A situação ontológica da cibernética, contudo, é caracterizada pelo fato de que o próprio aspecto do ser que a tradição ontológica exclui do tratamento científico é o coração temático e centro dessa nova disciplina. Já que é impossível negar a existência de novos métodos e de resultados positivos produzidos pela pesquisa em cibernética, não temos escolha a não ser desenvolver um novo sistema de ontologia junto a uma correspondente teoria de lógica. Os métodos lógicos que são usados faute de mieux ${ }^{[11]} \mathrm{em}$ cibernética pertencem à velha tradiçấo

classicamente exemplificada pelo motor térmico [heat engine], onde a energia disponível (i.e. entropia negativa) é uma função de uma diferença entre duas temperaturas. Nesse exemplo clássico, 'informação' e 'entropia negativa' se sobrepóem." (BATESON, 1999, p. 381, tradução nossa).

${ }^{11}$ Em francês, no original. "Na falta de algo melhor", em tradução livre. 
ontológica e não são suficientemente poderosos para analisar aspectos recentes da realidade que estão começando a emergir de uma teoria dos autômatos. (GÜNTHER, 2004, p. 1, tradução nossa).

Uma “ontologia cibernética”, como propóe Günther, deveria escapar aos dualismos engendrados pela tradição, já que os objetos de teorias emergentes, como a cibernética, não se enquadram em nenhum deles e não são totalmente explicados no quadro da ontologia e da lógica clássicas. Ao intento de desenvolver uma alternativa se dedica seu artigo de 1962. Não adentraremos, contudo, em suas teses centrais, mas apenas na problematização desses dualismos, a fim de compreender como eles operam. ${ }^{12}$

Segundo Günther, nesses dualismos, ocorre uma espécie de "enantiomorfismo", isto é, a simetria de estruturas que não se tocam nem se sobrepóem e que, dessa forma, como em uma imagem espelhada, são simetricamente opostas (GÜNTHER, 2004, p. 10). Espelhando-se mutuamente, os polos de cada dualismo mantêm-se cindidos por um abismo essencialmente intransponível ou, por outro lado, confundem-se, mas de uma perspectiva unitária que anula, invariavelmente, a possibilidade do outro polo - por exemplo, a totalidade do ente de uma perspectiva objetiva engloba, objetificando, qualquer forma de subjetividade, e vice-versa. Dessa maneira, a lógica bivalente ${ }^{13}$, amparada na ontologia monovalente, fica presa a uma dupla possibilidade de relaçáo entre os polos do dualismo, expressos nos caráteres proposicionais de conjunção $\left(p^{\wedge} \mathrm{q}\right)$ e disjunção inclusiva $(\mathrm{p} v \mathrm{q})$, no qual não se admite tertium intermédio. Essa dupla perspectiva é, de acordo com Günther (2004, p. 10), sumarizada, na lógica clássica, pelas duas expressóes De Morgan, a seguir:

\footnotetext{
${ }^{12}$ Aqui, será necessário um brevíssimo excurso metodológico com o uso de notaçóes simbólicas da lógica matemática, para facilitar a explicitaçấo dos argumentos de Günther. Assim, "p", "q" etc. indicarâo proposiçôes atômicas, " $\rightarrow$ " indicará implicaçâo ("se p ocorre, entâo q ocorre"), "三” indicará implicação mútua ("p ocorre se e somente se q ocorrer"), "_" indicará negação ("p não ocorre”), "v" indicará disjunção inclusiva ("p ocorre ou q ocorre ou ambos ocorrem”), "v" indicará disjunção exclusiva ("ou p ocorre, ou q ocorre”), $\mathrm{e}$ “^” indicará conjunção ("p e q ocorrem”).

${ }^{13}$ Essa lógica, a qual sustenta, conforme Günther, a própria tradiçẫo do pensamento ocidental, é preciso retomar de maneira sumária e com linguagem formal, ampara-se na duplicidade de valoresverdade, verdade e falsidade, e nos princípios de identidade, $(\mathrm{p} \equiv \mathrm{p})$, que reproduz logicamente, pela complementaridade da lei da não contradição, $\sim\left(p^{\wedge} \sim p\right)$ e do terceiro excluído ou tertium non datur, $(\mathrm{p} v \sim \mathrm{p})$, a monovalência ontológica e a bivalência de valor-verdade lógica. Sloterdijk faz referência, ao citar Günther, à desobediência, sobretudo, à última (cf. SLOTERDIJK, 2001, p. 216-218).
} 
DM1: $\left(\mathrm{p}^{\wedge} \mathrm{q}\right) \equiv \sim(\sim \mathrm{p} \vee \sim \mathrm{q})$
DM2: $(\mathrm{p} \vee \mathrm{q}) \equiv \sim\left(\sim \mathrm{p}^{\wedge} \sim \mathrm{q}\right)$

Entendamos "p" e "q" como os polos simetricamente opostos dos dualismos clássicos (como, por exemplo, "sujeito" e "objeto"). As expressóes acima, em sua mútua implicação, são circulares e tautológicas. Em DM1, o primeiro lado da expressão, indicando a totalidade do ente, diz que ambos ocorrem necessariamente e, assim, que a totalidade do ente engloba e confunde ambos os polos: "o todo do ente abarca p e q." Os dois polos têm de ocorrer e, portanto, é impossibilitada a não ocorrência de um deles (ou de ambos). Assim, ambos devem necessariamente ocorrer. Por outro lado, em DM2, na ocorrência de um dos polos (ou de ambos, mas não necessariamente), fica impossibilitada a não ocorrência concomitante dos dois polos e, por conseguinte, ao menos um dos polos deve necessariamente ocorrer: "O todo do ente possui necessariamente p ou q."

Günther aponta que analisar ambos seria ocioso, pois de ambos ele retiraria logicamente as mesmas conclusôes, e, por isso, suas investigações, no artigo, se voltam ao DM1, isto é, ao ponto de vista conjuntivo (GÜNTHER, 2004, p. 10-11). Segundo ele, nessa perspectiva, "é então possível fazer proposiçóes empiricamente conjuntivas sobre sujeitos e objetos em um contexto no qual todos os termos são uniformemente designados.” (2004, p. 11, tradução nossa) Assim, por exemplo, os dois extremos simetricamente opostos do idealismo e do realismo se encontram sob a mesma lógica: se $\left(\mathrm{p}^{\wedge} \mathrm{q}\right)$, de DM1, são compreendidos sob o espectro do idealismo, todos os entes são inseridos no âmbito do sujeito solipsista, cabendo aos entes exteriores, "reais", o âmbito do não-ser. E a recíproca é verdadeira: de uma perspectiva realista, a totalidade de (p $\wedge$ q) exclui o âmbito subjetivo do conhecimento, fadado à condição de supérfluo e enganador, criador de ilusôes e limitado às contingências. ${ }^{14}$

Para Günther, fazemos proposições dessa perspectiva no nosso discurso diário e, por isso mesmo, "tudo o que falamos sobre sujeitos é expresso em termos que designam objetos.” (2004, p. 11, tradução nossa). Quando, porém, voltamo-nos para linguagens mais técnicas e cuidadosas, como a linguagem

${ }^{14}$ Em Esferas III (SLOTERDIJK, 2004, p. 216-218), Sloterdijk alude ao mesmo dilema entre idealismo e realismo, que buscam responder à questâo "dos modos de ser do descoberto antes do descobrimento" (ibid., p. 216, tradução nossa), e faz referência a Latour e Heidegger, como pontos de encontro complementares, apesar de suas diferenças, as quais possibilitam a abertura de um "terceiro caminho" (ibid. p. 217, tradução nossa). 
formal, nos damos conta, segundo o autor, desse caráter enantiomórfico e, com isso, de sua insuficiência para tratar de fenômenos que escapam ao esquema dualista, como os sistemas complexos da cibernética nascente, os quais englobam objetos, sujeitos, ambiente etc., bem como um aglomerado de híbridos dos três. É necessário, diante de uma ontologia cibernética que não mais permite enquadrar o mundo em um esquema monovalente e nãocontraditório, recusar o princípio do terceiro excluído, possibilitando a assunção de outros valores (além dos valores objetivos de afirmação e negação), como o de "transjunção" (além de conjunção e disjunção, que faz com que a negação seja a transposição de uma variável em outra; 2004, p. 11), e, assim, a possibilidade de operar com sistemas complexos, ou seja, não só com os polos, mas com as mediaçóes também. A relevância da obra de Günther consiste em ser uma proposta de aplicação desse tipo de lógica (2004, p. 11), nisso residindo a importância do seu estudo para os problemas aqui discutidos.

A crítica de Günther à ontologia da tradição é análoga à de Latour, em Jamais fomos modernos (2013), quando o antropólogo põe em questão a divisão rígida dos ditos "modernos" entre cultura e natureza, ecoando o dualismo já preexistente na tradição entre forma e matéria, sujeito e objeto. O que chamamos de "modernidade", objetos naturais e fatos culturais, indissociáveis, consiste no esforço teórico por purificar uma regiáo do ente da outra, delimitando o escopo de alcance e ensejando que se possa analisar a natureza como natureza e a sociedade como sociedade. Conforme Latour, a operação de purificação (isto é, de separação entre natureza e cultura), que distingue os modernos de todo não-moderno, é só um construto teórico, o qual, apesar de sua eficácia, não garante a separação que pretende e, inclusive, gera paradoxos: enquanto o moderno vê a natureza como transcendente, determinista e sublime, ele a constrói nos laboratórios de ciência experimental; por outro lado, enquanto é dito que "todo o poder emana do povo", fazendo com que a sociedade seja um construto imanente de uma comunidade livre, o Estado-"Leviatâ" é posto como o todo-poderoso transcendente que controla irrestritamente a vida política da sociedade.

Se, desse modo, os modernos pretendem, como no DM2, separar os polos, isto é, postular ( p v q), não escapam eles à brecha aberta pela disjunção inclusiva de DM2, própria da lógica do terceiro excluído. $\mathrm{O}$ termo (p v q), que permite probabilisticamente (ou seja, em $25 \%$ de todas as combinaçóes) que os polos aconteçam simultaneamente, acaba gerando "híbridos", quer dizer, conjuntos de $\left(\mathrm{p}^{\wedge} \mathrm{q}\right)$ que agregam e misturam, justamente, os dois 
polos. O problema se manifesta, quando se percebe que o que caracteriza o moderno não é a separação dos polos por uma disjunção inclusiva (segundo a qual $[\mathrm{p} \wedge \mathrm{q}]$ em um quarto das possibilidades), mas por uma disjunção exclusiva, aos moldes do tertium non datur, que favorece exclusivamente a ocorrência de um dos polos, mas não dos dois. Dessa forma, se ( $\mathrm{p}$ v q) pretender ser uma disjunção exclusiva, ou seja, ( $\mathrm{p} \underline{\mathrm{v}} \mathrm{q})$, a fórmula $\left(\mathrm{p}^{\wedge} \mathrm{q}\right) \rightarrow$ ( $\mathrm{p}$ v q) mostra-se contraditória. ${ }^{15}$ Como visto, os modernos são modernos nas representaçóes, contudo, não-modernos na prática. Por outro lado, os pré-modernos, de acordo com Latour, tendem a ser, por suas representaçóes monistas, extremamente purificadores na prática, já que "todo monstro ${ }^{16} \mathrm{se}$ torna visível e pensável e expóe explicitamente graves problemas para a ordem social, o cosmos ou as leis divinas." (LATOUR, 2013, p. 46) Assim, podem apenas representar o DM1, em oposição ao DM2, e recaem em um tipo de paradoxo invertido: permitindo $\left(\mathrm{p}^{\wedge} \mathrm{q}\right)$ nas representaçóes, acabam, contra a implicação de DM1, possibilitando com que $(\sim p \vee \sim q)$, na prática, aconteça, ou seja, ou que um dos dois não ocorra, ou que os dois não ocorra ao mesmo tempo, mas impossibilitam o surgimento de $\left(\mathrm{p}^{\wedge} \mathrm{q}\right)$ fora das representações.

\footnotetext{
${ }^{15}$ Nas fórmulas De Morgan, o conectivo complementar ao da conjunção é o da disjunção inclusiva, não exclusiva, pois a última é totalmente inversa à expressão conectiva: ( $\mathrm{p}$ v q) diz simplesmente que não há possibilidade de $\left(\mathrm{p}^{\wedge} \mathrm{q}\right)$ - enquanto $(\mathrm{p} \vee \mathrm{q})$ admite $1 / 4$ de possibilidades de ocorrência simultânea de $\left(\mathrm{p}^{\wedge} \mathrm{q}\right)$.

16 "Monstro", aqui, também é sinônimo de "híbrido". O termo "monstruoso [Monströs]" (SLOTERDIJK, 2001, p. 151, tradução nossa), expresso no alemão também pela palavra Ungeheuer, o qual significa, além disso, "desmesurado", será importante para Sloterdijk, sobretudo em Esferas III (cf. id. 2004: "Aparece o monstruoso [Ungeheuer]" in "Prólogo: Nascimento da espuma", p. 79), e coaduna com a explicação de Latour (cf. 2013, p. 53) sobre a proliferação dos híbridos na contemporaneidade. Para Sloterdijk, os termos são intercambiáveis, como quando, em Domesticação do ser, o autor se refere à "trivialização do monstruoso [Ungeheuren]" (SLOTERDIJK, 2001, p. 152) e, em nota, cita uma obra de Friedrich G. Jünger "sobre a crítica do monstruoso trivial [Trivialmonströsen] no século 20" (ibid. nota 13). Uma traduçấo interessante a Ungeheuer, a que nos referiremos quando necessário, pode ser dada pelo termo "descomunal", pois ele parece implicar ambos os sentidos em uma confluência "titânica", diversa da ordem "olímpica" a que remete Heidegger com seus "deuses"; além disso, o termo Geheuer pode ser traduzido aproximadamente como "certo", "comum", "normal", como na frase "das ist mir nicht ganz geheuer" "isso não me é muito certo" ou, de modo menos literal, "isso me parece muito suspeito"). Logo, des-comunal é o que foge ao comum, ao normal, confluindo com a afirmação de que "o extraordinário [Äußerste] aparece, se aqui, no entanto, cabe falar em aparecer, na cotidianizaçáo do monstruoso [Veralltäglichung des Monströsen].” (ibid. p. 151, traduçáo nossa) Logo, o período de "situaçôes complexas" ou "médias", e não mais "extraordinárias", chegaria no momento em que o descomunal teria se tornado comum, cotidiano e, portanto, imperceptível, como nas décadas que sucederam, segundo Sloterdijk, à Segunda Guerra Mundial, quando, não mais explicitando os acontecimentos extremos em ocasiōes pontuais, tornou-se algo que não mais espanta e assombra (cf. ibid. p. 151-152).
} 
Se alterarmos as expressóes De Morgan, a fim de buscar um estado de coisas em que, apesar da purificação, se engendram híbridos — ou vice-versa —, obtemos: DM1’: $\left(\mathrm{p}^{\wedge} \mathrm{q}\right) \equiv(\sim \mathrm{p} \mathrm{v} \sim \mathrm{q})$; DM2’: (p v q) $\equiv\left(\sim \mathrm{p}^{\wedge} \sim \mathrm{q}\right)$. Seja interpretando "v" como disjunção inclusiva, seja como exclusiva, nas duas expressóes, do ponto de vista da lógica clássica, incorre-se em contradição, pois elas implicam que: em DM1', da existência necessária e simultânea dos dois polos, um ou outro polo (ou ambos) possa não existir; e, em DM2', que da existência facultativa de um dos polos (ou de ambos, no caso de disjunção inclusiva), a não existência necessária de ambos deve ser verdadeira. Embora Latour não expresse isso na simbologia lógica e não proponha necessariamente a assunção de uma lógica transjuncional aos moldes de Günther, é visível, a partir dessas contradições inerentes à condição dupla de purificação e tradução, que a lógica clássica é insuficiente, o que pode apontar para insuficiências na ontologia monovalente, tais como as apontadas pela cibernética.

Como Günther, preocupado com "sistemas" (GÜNTHER, 2004), Latour também está preocupado em abrir campo de investigação para as mediaçốes que, no registro latouriano, são chamadas de coisas (como “causas", em sentido próximo ao heideggeriano, significando a reunião de uma totalidade), quase-objetos (retirado de Michel Serres), caixas-pretas ${ }^{17}$,

\footnotetext{
${ }^{17}$ Esse uso, por Latour, do conceito cibernético de "caixa-preta" (black box) exemplifica sua afinidade com as discussóes da cibernética - conceito que, a propósito, também aparece em Bateson (1999) e que demonstra bem o que está em jogo: um sistema de tấo alta complexidade e hibridismo que, na cibernética, é simbolizado simplesmente por uma caixa preta. "A expressão caixa-preta é usada em cibernética sempre que uma máquina ou um conjunto de comandos se revela complexo demais. Em seu lugar, é desenhada uma caixinha preta, a respeito do qual não é preciso saber nada, senão o que nela entra e o que dela sai." (LATOUR, 2000, p. 14). Flusser, inclusive, em sua Filosofia da Caixa Preta (2011), escrito pela primeira vez em português, pensa no aparato fotográfico (e, por extensão, em toda tecnologia pós-histórica) como uma caixa-preta que ilude o fotógrafo: o fotógrafo, ao pensar que controla o aparelho (isto é, que é um sujeito autônomo e inaugurador de uma cadeia causal de acontecimentos), como um funcionário do aparelho, năo percebe que ele está, contudo, restrito à programação complexa já inscrita no aparelho - e, falando com Latour, a todo o coletivo que o aparelho pressupóe e esconde. "Pelo domínio do input [entrada] e output [saída], o fotógrafo domina o aparelho, mas pela ignorância dos processos no interior da caixa, é por ele dominado." (ibid. p. 44). Latour (2013) inclusive cita a câmera Kodak automática como exemplo de caixa-preta ecoando Flusser - e o atualizando, já que Flusser tratava de câmeras analógicas dos primórdios da fotografia já como caixas-pretas, enquanto Latour argumenta que a complexidade da câmera analógica automática (e, poderíamos dizer, hoje, da câmera digital) enquadra o aparato mais rigorosamente no conceito strictu de caixa-preta; "não é simplesmente uma questấo de número de aliados, mas de sua atuaçấo como um todo unificado." (ibid. p. 217) Se seguirmos a suspeita de que a concepçâo de técnica do antropólogo francês em muito se aproxima à de Sloterdijk (como discorreremos mais abaixo), abrem-se mais pontes interessantes entre as obras de Sloterdijk e Flusser, para além da "filosofia da migração" do pensador tcheco-brasileiro, citada por Sloterdijk em Esferas III (cf. FLUSSER, 2003; SLOTERDIJK, 2004).
} 
coletivos e redes ${ }^{18}$ (que, como disse Latour, são equivalentes às "esferas" às quais alude Sloterdijk [ LATOUR, 2009b]). As mediaçóes, as quais emergem a despeito da purificação levada a cabo pelos modernos, são mistos de natureza e cultura, englobam os discursos tanto quanto entes naturais, igualam os elementos divinos e não divinos e permitem aproximar os "modernos" (ou seja, o humanismo europeu, ou o "nós") e os "não modernos" ("eles", "outrem"), usualmente vistos sob o prisma antropocêntrico como partes de uma natureza transcendente a ser dominada e domesticada ou objetos de estudo - inclusive, para a antropologia clássica, que não se preocupava com uma abordagem simétrica (LATOUR, 2013).

A contínua tentativa de purificação moderna, inconsciente da proliferação sub-reptícia dos híbridos, continua até o extremo, segundo Latour, e culmina, passando pela separaçáo semiológica da linguagem com relaçáo aos extremos natureza-cultura, na distinção heideggeriana do ontológico frente a todo ôntico e em sua consequente assimetria (cf. LATOUR, 2013, p. 64). O que se inicia como uma tentativa de destruição da metafísica, que levaria a cabo o plano de alçar os coletivos à devida dignidade teórica, termina por reduzir todo o mundo ôntico - técnicas, ciências, política, sociologia, psicologia, antropologia, historiografia, economia, filosofia etc. - , visto sob o prisma do "puro arrazoado do ser (Ge-Stell), [...] destino inelutável (Geschick), [...] perigo supremo (Gefahr)" (LATOUR, 2013, p. 65), a resultado presente do esquecimento do ser. Para o pensador francês, Heidegger, suspendendo o De Morgan inteiro, em vista do simples ontológico, cai na armadilha dos modernos, a qual não é senão a armadilha da própria ontologia clássica e, dessa forma, mantém-se, também, um moderno. ${ }^{19}$

\footnotetext{
${ }^{18}$ Deixamos de lado aqui, por ora, em vista da brevidade do texto e de nosso escopo, as devidas nuances teóricas que Latour imprime aos conceitos aqui expostos.

${ }^{19}$ A questấo de saber se a crítica de Latour e Sloterdijk a Heidegger é justa é uma questão de difícil abordagem. Não intentamos, com este artigo, defender a legitimidade da crítica ou buscar desconstruíla. Limitamo-nos a tomar Heidegger, conforme lido por Sloterdijk, como uma possibilidade, entre outras, base válida para uma determinada construçẫo filosófica posterior, assim como, ao lermos Heidegger, admitimos sua interpretação de Nietzsche, para compreender o projeto ontológico do primeiro deles. Em certo sentido, ainda, vale notar que, lida a partir da argumentação de Günther (que também lera Heidegger, e era a ele, debitário), ou seja, lida com base na pressuposição de que "uma ontologia náo é nada além de uma prescrição bem genérica de como usar uma lógica no mundo existente" (GÜNTHER, 2004, p. 3, tradução nossa), a crítica de Latour e Sloterdijk não visaria à "ignorância" de Heidegger frente a lógicas não-clássicas - Heidegger, bem se sabe, foi professor de lógica e conhecia as pesquisas em lógica formal de seu tempo; seu pensamento pode ser lido, inclusive, em função do viés da lógica modal, como o faz Robson R. Reis (cf. 2014). Visaria, por outro lado, a uma possível pendência ontológica heideggeriana, isto é, à pendência de desconstruir a ontologia da tradição (ôntica), sem partir do princípio de que ela reduziria o todo à monovalência do "ente", verso à
} 
Qual a alternativa de Latour, portanto? Assumir uma postura símile à da cibernética, iniciando um outro tipo de antropologia, pós-estrutural e simétrica (ecoando estudos etnológicos e etnográficos, entre outros, de antropólogos como Philippe Descola e Tim Ingold, e reverberados na obra de antropólogos como Eduardo Viveiros de Castro e Marilyn Strathern), que permitiria conciliar ontologia e antropologia. ${ }^{20}$ Para isso, seria necessário elevar os objetos ao grau dos sujeitos, pondo em simetria a aparente assimetria moderna entre humanos e não-humanos e, junto disso, a assimetria entre natureza e cultura, trazendo as mediaçóes à tona como objetos de estudo teórico e ensejando conciliar o ôntico com o ontológico heideggeriano. Dessa forma, nos coletivos de Latour, também habitariam os deuses, como nos caminhos da floresta (Holzwege) do pensamento de Heidegger (LATOUR, 2013, p. 66).

É, pois, a partir dos apontamentos de Günther e Latour que Sloterdijk consegue deslocar-se da obra heideggeriana para poder investigar a antropogênese. Concordando com eles, o filósofo de Karlsruhe afirma que

[...] todos os objetos culturais são, por sua constituição, híbridos [Zwitter] com um "componente" espiritual e outro material, e [que] todo intento de dizer o que eles "propriamente" são nos limites da lógica bivalente e da ontologia monovalente termina irremissivelmente em reduçôes estéreis e abreviaçôes destrutivas. (SLOTERDIJK, 2001, p. 216, tradução e grifo nossos).

sua ausência, "nada", sem considerar, ao menos, um segundo valor ontológico, associado a, ao menos, um terceiro valor lógico. Com efeito, no lugar do "nada", Heidegger teria introduzido o "ser" ou o Ereignis como nẫo-fundamento (Ab-grund) do ente na totalidade — mas o ente continuaria sob o primado da monovalência: ou "ser" (ente), ou nada (Ereignis). Sloterdijk (o qual reconhece que a obra de Heidegger abre essa possibilidade) e Latour parecem sugerir, com uma ontologia do híbrido, não a abolição de uma diferença ontológica, mas sua imanência na própria hibridagem. Talvez se possa interpretar que um segundo valor ontológico, nesse sentido, seria a inserção do ser no domínio não do mero ente, mas da "realidade" como um todo - abdicando-se de se falar em "nada". Ou melhor: "admitimos não apenas ser mas também nada. Ser é e nada é. Além do sim e do năo, em um nível teórico, uma terceira opção sempre existe. Através disso, nós damos à realidade da diferença uma vantagem sobre o valor da identidade e deixamos serem reais a diferença, o singular e o nada." (SLOTERDIJK, 2016, p. 314-315, tradução nossa) Assim, o "objeto" (ou melhor, a "coisa", que congrega todo um coletivo) já traria consigo ôntico e ontológico, bem como natural e cultural.

${ }^{20}$ É necessário ressaltar que a "virada ontológica" da antropologia não necessariamente se dá do mesmo modo em diferentes antropólogos, e que diversas vezes discordâncias absolutas com relação a pressupostos fundamentais estão em jogo entre os nomes citados, como, por exemplo, a divergência entre Viveiros de Castro e Descola, a respeito do animismo (cf. VIVEIROS DE CASTRO, 2015, p. 77ss.), ou a divergência entre os pressupostos antropológicos de Sloterdijk e Viveiros de Castro, a despeito da proximidade de ambos com a obra de Latour (cf. PITTA, 2019). Quanto à multiplicidade de posiçóes dentro disso que costumam chamar de "antropologia pós-estruturalista" ou "virada ontológica”, cf. CHARBONNIER; SALMON; SKAFISH, 2017; HOLBRAAD; PETERSEN, 2017. 
Assim, o que Heidegger aponta como errância dos tempos da Gestell não passa, para Sloterdijk, da tentativa metafísica, desde Platão e Aristóteles, de dominar, embora não necessariamente de propósito, a totalidade do ente, compreendido por via da ontologia monovalente, pela lógica bivalente, ainda que o filósofo de Meßkirch tenha um papel crucial na desconstrução do discurso da tradição, ao já apontar uma tendência substancialista da ontologia ocidental (SLOTERDIJK, 2001, p. 216). Tem-se, nessa dualidade, uma dialética do senhor e do escravo que perdura por toda a história da tradição, na qual um polo se sobrepóe ao outro (SLOTERDIJK, 2001, p. 224). O humanismo clássico é, nesse sentido, o domínio do humano (forma, sujeito, espírito, cultura) sobre todo componente não-humano (matéria, objeto, natureza) e, nessa mesma lógica, a revolta do náo humano contra o predomínio humano.

A cibernética, por outro lado, apesar de não resolver tudo, parece conferir novo alento às investigaçóes sobre os híbridos, e, para Sloterdijk, a noção de "informação" insere-se "como terceiro valor entre o polo da reflexão e o polo da coisa” (SLOTERDIJK, 2001, p. 218, tradução nossa), ou entre os polos da forma e da matéria, da cultura e da natureza. ${ }^{21}$ Os híbridos, tal como a bomba a vácuo que Latour (2013) usa de exemplo para explicar suas mediaçóes, possuem carga tanto da natureza transcendente, mas imanente no laboratório, quanto do contexto social imanente, mas transcendente pelo contrato social (LATOUR, 2013, p. 31). São, portanto, híbridos de objeto (passíveis de valor-verdade) e contexto (possuindo valores para além da bivalência lógica, que se refere ou a objetos reais, ou a fenômenos subjetivos). ${ }^{22}$ Assim, mesmo construídos por sujeitos, os híbridos são também reais e objetivos, "armazéns da história de sua produçâo ou memórias ligadas a coisas" (SLOTERDIJK, 2001, p. 218, tradução nossa), e é necessário, de acordo com Sloterdijk, que se conceba uma ontologia ao menos bivalente e uma lógica ao menos trivalente, a fim de lidar com o conceito de informação para além da noção segundo a qual informação é indício de que "o próprio

\footnotetext{
${ }^{21}$ Vale citar aqui Flusser, para quem a entropia, isto é, a "segunda lei da termodinâmica, [...] diz que toda matéria tende a perder a sua forma (sua informação).” (FLUSSER, 2017, p. 198). A informação e a entropia estariam, assim, entre matéria e forma, na própria tensẫo entre "in-formação" e "deformação".

${ }^{22}$ Extrapolando, de acordo com Günther, para além dos valores "verdadeiro" (1) e "falso" (2), para valores de tipo " 3 ", “4” etc. Se "1" e "2" se referem a objetos, passíveis de verificação, "3" pode aludir ao ambiente desses objetos, por "exclusão" dos objetos, e "4", ao sujeito, por "exclusão" do ambiente. Chega-se a esses valores, grosso modo, admitindo o terceiro excluído e transformando o operador de negação em um operador "transjuncional": a negação de 1 (verdade) gera 2 (falsidade), contudo, a negação de 2 gera 3, a de 3, 4, e assim sucessivamente (cf. GÜNTHER, 2004, p. 57-59).
} 
da linguagem está reduzido à transmissão de sinais, isto é, a sua atrofia." (HEIDEGGER, 1989, p. 26, tradução nossa). Por conseguinte, informação e mediação são termos coimplicados, e é necessário, para pensar a emergência de ambos, "conquistar o tertium datur" (SLOTERDIJK, 2001, p. 218, tradução nossa), ou seja, utilizar-se de um instrumentário lógico que recuse o princípio do terceiro excluído em favor do hibridismo.

Conforme Sloterdijk, trasladar-se a um outro tipo de concepção ontológica de mundo também implica reavaliar o sentido clássico da técnica e, com isso, reavaliar a "equação de ser humano e clareira", essa agora impensável “sem sua origem tecnógena." (SLOTERDIJK, 2001, p. 224, tradução nossa). Em uma época na qual a purificação ontológica não pode mais ocultar por assepsia teórica o surgimento do híbrido, isto é, "após a exploração da latência" ter-se efetuado, como questiona Pessanha (2016, p. 85),

[...] como encontrar um lugar ainda escuro e imune às explicações; um lugar-quadrindade (Geviert), onde entes como vírus e partículas não tivessem cidadania? Para Sloterdijk, um lugar assim, próximo do "frio vento do exterior" [...] teria de ser ele mesmo, paradoxalmente, produzido pela engenharia política e concedido não pelo ser, mas pela "produção técnica e assessoramento jurídico".

Se a clareira e o Da-sein agora devem ser vistos sob o prisma do híbrido e se devem ser concebidos a partir de uma relação simétrica entre o ôntico e o ontológico, eles acabam tendo de ser parelhos aos coletivos de humanos e nãohumanos de Latour, como aqueles envolvidos nos experimentos dentro de um laboratório, congregando realismo e antirrealismo, transcendência e imanência, natureza e cultura, ou seja, partindo de uma abordagem construtivista dos próprios coletivos. Para Sloterdijk, essa empreitada constitui uma espécie de "reconstrutivismo fantástico", que visa a evitar recaídas em um evolucionismo que supóe o ser do humano o qual será investigado ou, por excesso de zelo explicativo, se esquece do ponto de partida "na clareira e no estado atual da civilização.” (SLOTERDIJK, 2001, p. 154, tradução nossa).

Dessa forma, para Sloterdijk, "estamos sobre um plano onde há principalmente a técnica." ${ }^{23}$ (2001, p. 245, traduçáo e grifo nossos). Não basta mais, segundo ele, pensar a produção tecnógena do humano na clareira

${ }^{23}$ Em francês, no original: "Nous sommes sur un plan où il y a principalement la technique." (SLOTERDIJK, 2001, p. 225) 
de uma perspectiva alotécnica ${ }^{24}$, como uma operação de "incisôes violentas e contranaturais [pelos sujeitos] nos objetos encontrados [Vorgefundene] e [de] empregar matérias para fins indiferentes ou estranhos a elas." (2001, p. 226, tradução nossa) Em direção oposta à alotécnica, Sloterdijk defende, em uma era na qual a informação é a nova ordem conceitual, o processo de antropogênese de uma perspectiva homeotécnica ${ }^{25}$, na qual "as 'matérias' são concebidas desde seu sentido próprio e incluídas nas operações em virtude de sua máxima idoneidade." (SLOTERDIJK, 2001, p. 227, tradução nossa) Mais uma vez, o filósofo alemão está dialogando com Latour, bem como com a tradição da cibernética, da antropologia, da biologia e da ecologia. Com intuito semelhante ao do pensador francês, Sloterdijk defende que a técnica, na contemporaneidade, deve ser visada na confluência que possui com a própria noção de mediação e seu correlato, o coletivo.

Tal confluência, que já se dá em Jamais fomos modernos (LATOUR, 2013), aparece em outro livro de Latour, A esperança de Pandora (2001), no capítulo onde o teórico francês discute a técnica em oposição à postura de Heidegger. Se, para o pensador do ser, nas palavras do pesquisador francês, "uma tecnologia jamais é um instrumento, uma simples ferramenta" e "nós mesmos nos tornamos instrumentos para o fim único da instrumentalidade em si”, “enquadrados por esse Gestell” (2001, p. 203), para o antropólogo francês, tal concepção se encontra, mais uma vez, no mesmo domínio simétrico que sua antítese apologética.

Aqui, estão em tensão duas formas de relação tecnológica e ecológica entre sujeito e meio: "determinismo do meio" e "instrumentalismo do meio", na qual a primeira, para nos apropriarmos do exemplo da discussão sobre o porte de armas de fogo que Latour explora, no livro, se encaixa no slogan "armas [i.e. meios] matam pessoas" (apud LATOUR, 2001, p. 203), enquanto a segunda melhor se entende com o slogan "armas não matam pessoas; pessoas [i.e. sujeitos] matam pessoas” (apud LATOUR, 2001, p. 203). Na primeira, o meio é determinista, e o sujeito nada pode contra a influência do instrumento, que o domina; na segunda, por outro lado, levada ao extremo, o meio é mero instrumento neutro de um sujeito de posse de seus intentos pessoais, e o meio não influencia sua

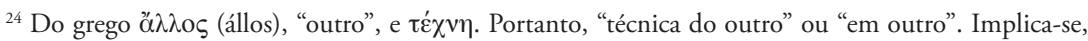
nisso, a diferença entre um conformador técnico (atuante) e um conformado (atuado), proveniente da noção aristotélica de $\tau \dot{\varepsilon} \chi v \eta$ como conformaçấo causal de matéria.

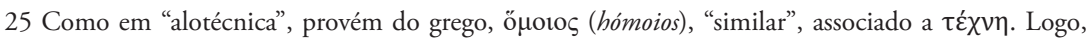
"técnica do mesmo" ou "no mesmo", implicando similitude entre o atuante e o atuado e inversão mútua da dinâmica.
} 
intenção. A Gestell heideggeriana parece flertar com a primeira, não fosse pelo fato de que ela não se reduz a um instrumento qualquer. Contudo, levando-se em conta que a Gestell é o próprio modo de desencobrimento da clareira, destino do ser, não é difícil associá-la a "um monstro nascido entre nós que já devorou suas parteiras involuntárias", como pensa Latour (2001, p. 203), diferentemente

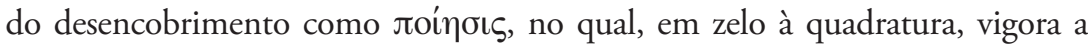
liberdade do humano enquanto pastor do ser.

Para o teórico francês, nenhuma das concepçóes dá conta da emergência dos híbridos, como a situação do cidadão portando a arma (ou do fotógrafo portando sua câmera, de Flusser), tornado "arma-cidadão" ou "cidadão-arma" (LATOUR, 2001, p. 206), e escondem o próprio teor coletivista da técnica, quer dizer, sua condiçáo de congregadora ou agenciadora de um conjunto de atuantes e aliados, "sujeitos" e "objetos", humanos e não-humanos. Nesse sentido, é necessário relevar que a técnica, vista para Latour do prisma de um modus operandi (2001, p. 240), é nada mais do que uma mediação que permite o coletivo e que depende de uma mútua interferência e modificação entre os polos (2001, p. 205-208), de uma composição de diferentes agentes, humanos e não-humanos, implicados todos na "caixa-preta" de dado sistema, no qual a ação é resultado do próprio coletivo de atuantes (2001, p. 208-210), de um entrelaçamento e condensação de espaço e tempo (2001, p. 210-213), no qual as açóes dos vários agentes "subsistem (no tempo) e se estendem (no espaço)" (2001, p. 240), agregando várias etapas na concretização do aparato, e de uma transposição contínua de fronteiras entre signos e coisas (2001, p. 213-219), significados e significantes, que faz com que a relação entre os diferentes atores seja de uma qualidade tanto simbólica quanto concreta, nas duas direçôes (dos não-humanos para os humanos e no sentido inverso). Logo, nem a arma nem o cidadão são, sozinhos, polos determinantes na construção do coletivo "armacidadão”, mas participam mutuamente, em interferência recíproca, na relação.

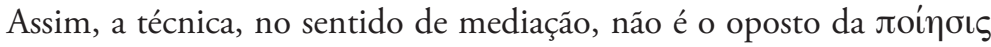
dos antigos artesãos, que se constituía do mesmo modo, seguindo as mesmas etapas (LATOUR, 2001, p. 223-224), e a distinção quase de natureza entre uma técnica originária enquanto uma produção que deixa vigorar o ente no seu ser próprio e uma técnica moderna, tecnologia, enquanto provocação que expóe o ente à luz, sob a faceta esvaziada de mero estoque, não faz mais sentido, devendo ser subvertida (LATOUR, 2001, p. 223). "A diferença”, para Latour, "consiste em que o último [a técnica moderna] translada, permuta, recruta e mobiliza um número maior de elementos mais intimamente conectados, 
com um tecido socio-natural mais finalmente urdido e complexificado que o primeiro.” (2001, p. 224). A técnica moderna, por conseguinte, evidencia mais a "descomunalidade", a "monstruosidade" do próprio coletivo. Se entendida

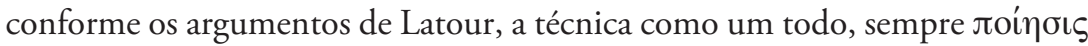
enquanto $\tau \dot{\varepsilon} \chi v \eta$, mesmo em sua forma moderna de desvelamento, deve ser reposta na vizinhança de um outro importante conceito heideggeriano:

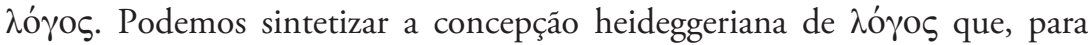
ele, é a experiência originária do que seria a linguagem, da seguinte maneira: reunir um conjunto em uma unidade e deixar com que o conjunto vigore por si mesmo (LATOUR, 2001, p. 232-233). Dessa forma, pode-se compreender por que Sloterdijk (2001, p. 222, tradução nossa) assevera que

[o humano] é uma possibilidade regional da clareira e uma energia local de reunião. É um centro de reuniáo da verdade e do poder, mas não de todas as coisas: nisso enraíza-se o conceito pós-metafísico de logos [ $\lambda$ ó $\gamma \circ \varsigma]$

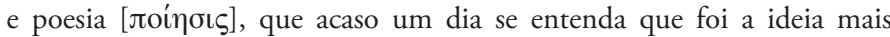
importante de Heidegger.

O humano é polo de um agenciamento, de um coletivo, isto é, da

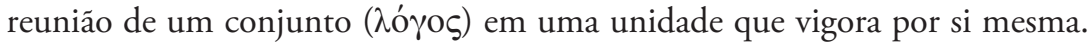
Todavia, o humano não age sozinho; junto dele, todos os não-humanos atuam na constituição do coletivo (ou, já antecipado em termos sloterdijkianos, da esfera). Assim, se a clareira é o тó mortais e imortais, céu e terra, humanos e não-humanos, cultura e natureza, ontológico e ôntico, para Sloterdijk, ela será compreendida em termos técnicos

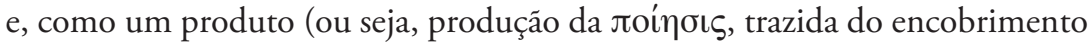
ao descobrimento), deve ser pensada também a partir de suas relaçóes e métodos ônticos de produção.

Produto de que ou de quem? De Deus, da transcendência absoluta? Dos homens, da imanência social? Se a clareira é resultado da própria história de formação da clareira, ela deve ser concebida em um processo autógeno, mas se ela é, por si só, um produto técnico híbrido (e, por isso, não só ontológico como ôntico), concebido em sua confluência com um processo de mediação entre humanos e não-humanos, ela deve também ser visada em função de uma perspectiva que, congregando ontologia e antropologia, adversa aos intentos de Heidegger, permita pensar seu surgimento antropológico a partir de uma posição intermediária, entre o "acima" da transcendência e o "abaixo" 
da imanência, em uma constituição de atuantes não-humanos ou, mais especificamente, "pré-humanos"26 (SLOTERDIJK, 2001, p. 157).

Uma antropologia que, enfim, pautasse seus aportes em uma ontologia cibernética possibilitaria o intento de Sloterdijk de repensar a clareira ontológica heideggeriana junto à sua constituição ôntica. À investigação sloterdijkiana, a qual configura seu "reconstrutivismo fantástico" como uma narrativa de "fantasia filosófica" (2001, p. 154, tradução nossa), respeitando o ponto de partida heideggeriano do ente humano como constituinte de um mesmo Da-sein, mas não supondo o pré-humano como um ente que em potência (e, portanto, por natureza), já é um ontológico habitante da clareira, o autor batiza de "ontoantropologia", espécie de correlato da antropologia simétrica de Latour, cujo objeto de investigação é o próprio movimento de antropogênese do humano. Poderíamos pensá-la, com certa liberdade, como uma "antropologia cibernética": uma ontoantropologia do ponto de vista do tertium datur e que favoreceria pensar a subjetividade como um coletivo que envolve "sujeitos", "objetos" e "meio". Os apontamentos sobre uma tal antropologia cibernética — que, para Sloterdijk, tomará a forma de uma "esferologia" - deverão, contudo, ficar para outra ocasião.

PITTA, M. F.; WEBER, J. F. Conquering the Tertium Datur: Sloterdijk in defense of a "cybernetic anthropology" (between Heidegger, Günther and Latour). Trans/form/ação, Marília, v. 43, n. 1, p. 189-212, Jan./Mar., 2020.

${ }^{26}$ Esse termo não possui nada de misterioso. Com ele (ou com seu relativo, "pré-sapiens"), simplesmente, Sloterdijk aponta especulativamente para certa espécie de vivente que, participando inconscientemente de determinadas etapas da antropogênese, transfigurou-se na espécie que costumamos chamar de "humano" (ou homo sapiens). Ele cumpre uma função "fantasticamente reconstruída" e "paleo-ontológica" do gênero "homo", que os paleontólogos costumam utilizar para definir a cisão entre o humano e o primata primitivo Australopithecus (cf. MCHENRY, 2009, p. 242) — com a diferença de que, para Sloterdijk, pensar o pré-humano não implica em pensar em um gênero ou espécie "a meio caminho da evolução", como se visasse o humano, mas serve apenas como uma das duas âncoras (o pré-humano e a clareira) para reconstruir especulativamente uma antropogênese ôntico-ontológica. Aqui, fica claro que um dos pressupostos de Sloterdijk está na tese paleontológica de evolução unirregional do homo sapiens, que postula que o humano surgiu primeiramente na África e, só posteriormente, se difundiu pelos continentes, substituindo outras espécies como o homo erectus e, posteriormente, o homo neanderthalis. Apesar de fortes evidências sustentarem a tese unirregional, não há consenso absoluto entre os paleontólogos, atualmente, na disputa entre as teses do unirregionalismo e do multirregionalismo (isto é, de que o homo sapiens possa ter surgido em outras regióes do planeta quase que simultaneamente). 
ABSTRACT: Martin Heidegger developed an analysis of metaphysics and technology that questioned its ontological presupositions. However, Peter Sloterdijk, author of a revision of the Heideggerian clearing (Lichtung), under the title of Domestication of being: clarifying the clearing, argues that Heidegger suffers from the same illness he criticizes: an abeyance relative to classical ontology, which, after Plato and Aristotle, separated Being and Nothingness, grounded the logical bivalence, excluding any third possibility, and allowing for the metaphysical dualisms. Following the anthropologist Bruno Latour, who has showed that "Modernity" is a belief in the split between the poles of form and matter, of subject and object, of nature and culture, Sloterdijk also assigns to Heidegger the dependence on classical ontology on the level of the split between ontological and ontic. In this respect, what does Sloterdijk suggest? An alternative to classical ontology in the cybernetics of Wiener and Günther, in order to reattach the links broken by Heidegger between ontology and anthropology. This work aims to articulate Sloterdijk's critique, Latour's enquiry and Günther's ontological-logical revision, in order to open field for an understanding on the Sloterdijkian project of thinking anthropology from cybernetical hypotheses.

KeYwords: Anthropology. Cybernetics. Non-classical Logics. Metaphysics. Ontology.

\section{REFERÊNCIAS}

ASHBY, W. Ross. An Introduction to Cybernetics. London: Chapman \& Hall, 1956.

BATESON, Gregory. Steps to an Ecology of Mind. Prefácio de Mary C. Bateson. Londres: The University of Chicago Press, 1999.

CASANOVA, Marco A. Compreender Heidegger. 3. ed. Petrópolis: Vozes, 2012 (Série "Compreender").

CHARBONNIER, Pierre; SALMON, Gildas; SKAFISH, Peter. Comparative metaphysics: ontology after anthropology. Londres: Rowman \& Littlefield, 2017.

FLUSSER, Vilém. The freedom of the migrant: objections to nationalism. Tradução de Kenneth Kronenberg. Chicago: University of Illinois Press, 2003.

FLUSSER, Vilém. Filosofia da Caixa Preta: ensaios para uma futura filosofia da fotografia. São Paulo: Annablume, 2011.

FLUSSER, Vilém. O mundo codificado: por uma filosofia do design e da comunicação. Introd. e org. de Rafael Cardoso, tradução de Raquel Abi-Sâmara. São Paulo: Ubu, 2017.

GÜNTHER, Gotthard. Cybernetic ontology and transjunctional operations. Vordenker, Neuss, 2004. Disponível em: http://www.vordenker.de/ggphilosophy/gg_cyb_ontology. pdf. Acesso em: 6 set. 2016.

HEIDEGGER, Martin. Die Grundprobleme der Phänomenologie. Frankfurt am Main: Vittorio Klostermann, 1975 (Col. "Gesamtausgabe”, v. 24).

HEIDEGGER, Martin. Wegmarken. Frankfurt am Main: Vittorio Klostermann, 1976 (Col. "Gesamtausgabe", v. 9).

HEIDEGGER, Martin. Unterwegs zur Sprache. Frankfurt am Main: Vittorio Klostermann, 1985 (Col. "Gesamtausgabe”, v. 12). 
HEIDEGGER, Martin. Zollikoner Seminare: Protokolle - Gespräche - Briefe. Frankfurt am Main: Vittorio Klostermann, 1987 (Col. "Gesamtausgabe”, v. 89).

HEIDEGGER, Martin. Überlieferte Sprache und technische Sprache. St. Gallen: Erker, 1989.

HEIDEGGER, Martin. Vorträge und Aufsätze. Frankfurt am Main: Vittorio Klostermann, 2000 (Col. "Gesamtausgabe", v. 7).

HEIDEGGER, Martin. Identität und Differenz. Frankfurt am Main: Vittorio Klostermann, 2006 (Col. "Gesamtausgabe”, v.11).

HEIDEGGER, Martin. Zur Sache des Denkens. Frankfurt am Main: Vittorio Klostermann, 2007 (Col. "Gesamtausgabe”, v. 14).

HEIDEGGER, Martin. Ser e tempo; Sein und Zeit. Ed. bilíngue. Trad., org., notas etc. de Fausto Castilho. Campinas: Unicamp; Petrópolis: Vozes, 2012 (Col. "Multilíngues de Filosofia Unicamp”).

HOLBRAAD, Martin; PEDERSEN, Morten A. The ontological turn: an anthropological exposition. Cambridge: Cambridge University Press, 2017.

LATOUR, Bruno. Ciência em açâo: como seguir cientistas e engenheiros sociedade afora. Tradução de Ivone C. Benedetti. São Paulo: UNESP, 2000.

LATOUR, Bruno. A esperança de Pandora: ensaios sobre a realidade dos estudos científicos. Tradução de Gilson C.C. de Sousa. Bauru: EDUSC, 2001.

LATOUR, Bruno. A cautious Promotheus? A few steps toward a Philosophy of Design (with special to Peter Sloterdijk). In: ANNUAL INTERNATIONAL CONFERENCE OF THE DESIGN HISTORY SOCIETY, 2008. Proceedings. Falmouth, p. 2-10, set. 2009a. Disponível em: http://www.bruno-latour.fr/sites/default/files/112-DESIGNCORNWALL-GB.pdf. Acesso em: 4 maio 2016.

LATOUR, Bruno. Spheres and networks: two ways to reinterpret globalization, Harvard Design Magazine, Cambridge p. 138-144, 2009b. Disponível em: http://www.brunolatour.fr/sites/default/files/115-space-harvard-gb.pdf. Acesso em: 4 maio 2016.

LATOUR, Bruno. Jamais fomos modernos: ensaio de antropologia simétrica. Tradução de Carlos I. Costa. São Paulo: Editora 34, 2013.

LIMA, Carlos C. Causalidade e auto-organização. In: PUENTE, Fernando R.; VIEIRA, Leonardo A. (org.). As filosofias de Schelling. Belo Horizonte: UFMG, 2005. p. 253-286.

MCHENRY, Henry M. Human evolution. In: RUSE, Michael; TRAVIS, Joseph (org.). Evolution: the first four billion years. Cambridge: Harvard University Press, 2009.

MORAN, Emílio F. Adaptabilidade humana: uma introdução à Antropologia Ecológica. Tradução de Carlos E.A. Coimbra, Marcelo S. Brandão e Fábio Larsson. 2. ed. São Paulo: EDUSP; SENAC São Paulo, 2010 (Col. "Ponta”).

PESSANHA, Juliano G. Peter Sloterdijk: virada imunológica e analítica do lugar. 2016. Tese (Doutorado) - Faculdade de Filosofia, Letras e Ciências Humanas, Departamento de Filosofia, Universidade de São Paulo, São Paulo, 2016. 
PITTA, Maurício F. Do problema da espacialidade em Heidegger à esferologia de Sloterdijk. Synesis, Petrópolis, v. 9, n. 1, p. 141-164, jan./jul. 2017.

PITTA, Maurício F. Um ensaio para um "Anti-Orfeu”: Perspectivismo cosmológico como contraponto à esferologia de Sloterdijk. Griot: Revista de Filosofia, Bahia, v. 19, n. 3, p. 177-196, out. 2019.

REIS, Robson R. Aspectos da modalidade: a noção de possibilidade na fenomenologia hermenêutica. Rio de Janeiro: Via Vérita, 2014.

SLOTERDIJK, Peter. Sphären I (Mikrosphärologie): Blasen. Frankfurt am Main: Suhrkamp, 1998.

SLOTERDIJK, Peter. Sphären II (Makrosphärologie): Globen. Frankfurt am Main: Suhrkamp, 1999.

SLOTERDIJK, Peter. Nicht gerettet: Versuche nach Heidegger. Frankfurt am Main: Suhrkamp, 2001.

SLOTERDIJK, Peter. Sphären III (Plurale Sphärologie): Schäume. Frankfurt am Main: Suhrkamp, 2004.

SLOTERDIJK, Peter; HEINRICHS, Hans-Jürgen. Die Sonne und der Tod: dialogische Untersuchungen. Frankfurt am Main: Suhrkamp, 2016.

VALENTIM, Marco A. O ente enquanto outrem: nota sobre a possibilidade de uma ontologia não-antropogenética. Sopro, Florianópolis, n. 85, p. 5-20, mar. 2013.

VIVEIROS DE CASTRO, Eduardo. Metafísicas canibais: elementos para uma antropologia pós-estrutural. São Paulo: Cosac Naify, 2015.

VOLPI, Franco. Heidegger e Aristóteles. Tradução de José Trindade dos Santos. São Paulo: Loyola, 2013.

VON BERTALANFFY, Ludwig. General system theory: foundations, development, applications. New York: George Braziller, 1969.

VON UEXKÜLL, Jakob. A foray into the world of animals and humans. A theory of meaning. Tradução de Joseph D. O’Neil. Posfácio de Geoffrey Winthrop-Young. Minnesota: University of Minnesota Press, 2010.

WIENER, Norbert. Cibernética e sociedade: o uso humano de sêres humanos. Tradução de José Paulo Paes. São Paulo: Cultrix, 1958.

WIENER, Norbert. Cybernetics: or control and communication in the animal and the machine. 2.ed. Cambridge: The MIT Press, 1985.

SILVA, L. C. On the sentiment's conceptual negativity or the schopenhauerian philosophy of language. Trans/form/ação, Marília, v. 43, n. 1, p. 189-188, Jan./Mar., 2020.

Recebido: 20/07/2017

Aceito: 24/10/2019 